\title{
Physical Activity Improves Mental Rotation Performance
}

\author{
Petra Jansen, Stefanie Pietsch
}

Institute of Sport Science, University of Regensburg, Regensburg, Germany.

Email: petra.jansen@psk, uni-regensburg.de

Received December $23^{\text {rd }}, 2009$; revised February $28^{\text {th }}, 2010$; accepted April $1^{\text {st }}, 2010$.

\begin{abstract}
Even there seemed to be general knowledge that physical activity enhanced spatial cognitive performance almost none experimental studies on this influence exist. For that the influence of physical activity on mental rotation performance is investigated in this study. Mental rotation is the ability to imagine how an object would look if rotated away from the original orientation. Two groups of 44 students of educational science each solved a psychometrical mental rotation task with three-dimensional block figures. After this, the participants of the physical activity group took part in a sport lesson, whereas the participants of the cognitive activity group attended an oral lesson of kinematics. Both lessons took 45 minutes. Thereafter, all participants solved the mental rotation task again. The results showed that the participants of the physical activity group improved their mental rotation performance whereas the participants of the cognitive activity showed no improvement.
\end{abstract}

Keywords: Physical and Cognitive Performance, Pedagogic Implication

\section{Introduction}

It is the main goal of this paper to investigate the influence of physical activity on cognitive performance, especially on spatial cognition. This relation was already formulated by Piaget [1]. In recent developmental research it is postulated that activity dependent multi- modal experience is a core mechanism creating developmental change [2]. This postulated relation is also evident in psychological research, where the relation between motor development and cognitive development is investigated in more detail in infancy [3] as well as in older adults [4]. Furthermore it was shown, that a dysfunction in motor development is often associated with a dysfunction in cognitive development and vice versa [5-7]. In sport science, a meta-analysis examined the relationship between motor and cognitive development $[8,9]$ and revealed a positive correlation even though the results are, as a rule, restricted to adults.

This evidence from educational, psychological and sport science, is confirmed by the specific assumption [10] that motor development and movement experience are relevant factors for cognitive performance, especially for spatial ability [11]. Spatial abilities are cognitive processes composed of visualization, orientation and mental rotation [12]. Within these factors, mental rotation, i.e., the ability to imagine how an object would look if rotated away from the orientation, in which it is actually presented [13], is an important and well-investigated factor. Spatial cognition is fundamentally relevant for problem solving [14], mathematics [15] and science [16].

What is almost completely absent until now is the experimental investigation of physical activity on a spatial cognition task. According to our knowledge, only one study investigated the effect of a specific motor training in adults on mental rotation ability [17]. The authors provided evidence that a program of juggling training over a period of three months improved mental rotation performance in adults, compared to a control group that did not receive any training. Because the physical activation training in the former study lasted over three months, we were interested if a short physical activation (45 minutes) improved mental rotation as well. As a control group we chose a kind of cognitive activation. Students had to listen to a theoretical lesson of physical activation while they were allowed to ask something and to answer questions. Both groups were chosen because both were real educational situations, which enhance the ecological validity.

Because of the study of Jansen et al. [17] and the theoretical relation between motor and visual-spatial abilities [10], it is assumed that students would profit more from a physical activity lesson than from a theoretical lesson 
regarding their mental rotation ability. This hypothesis is supported by studies of central nervous processes. Neuroscientific studies showed a motor cortex activation during mental rotation [18] as well as an increasing plasticity after training of juggling [19] in exactly that brain area (intraparietal sulcus) which is involved in mental rotation [20]. This evidence gives a hint for the assumed influence of physical activity on mental rotation performance.

\section{Method}

\subsection{Participants}

88 students of educational science with sport science as the main subject participated, 43 males (mean age: 23.66 years) and 45 females (mean age: 22.46 years). The students participated in the physical activity group (EG, 22 men and 22 females) or in the cognitive activity group, (CG, 21 men and 23 females). All participants gave their written consent for participation.

\subsection{Material and Procedure}

For the measurement of the mental rotation performance the paper-pencil mental rotation test, MRT, (Version A) redrawn by Peters et al. [16], which was originally developed by Vandenberg and Kuse [21] with figures created by Shepard and Metzler [13], was used. This test consists of two sets of 12 items each. Each item contains respectively a target figure on the left side and four sample stimuli that show the target figure in rotated versions. Two of the four sample stimuli were the same than the target figure. Participants had to find out these two items, which were the same. Figure 1 shows an example of the items used.

In the original test of Peters et al. [16], the items were presented to the participants on four DIN A-4 sheets with six items per sheet and a 3-min deadline to solve a set of 12 items (6 min for the entire test). Instructions were
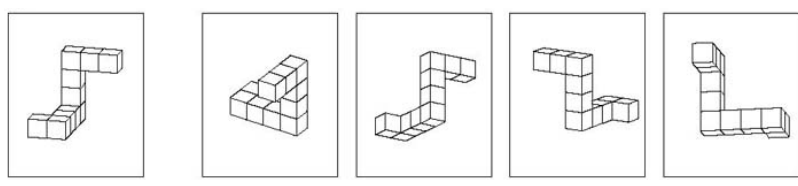

(a)
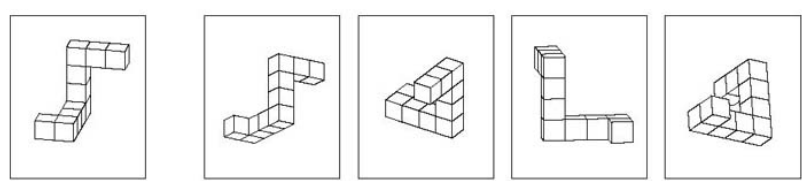

(b)

Figure 1. An example of two items used in the Mental Rotation Test. The target figure is shown on the left and the four sample stimuli are presented aside. Always two of these are identical to the target figure but are rotated in depth

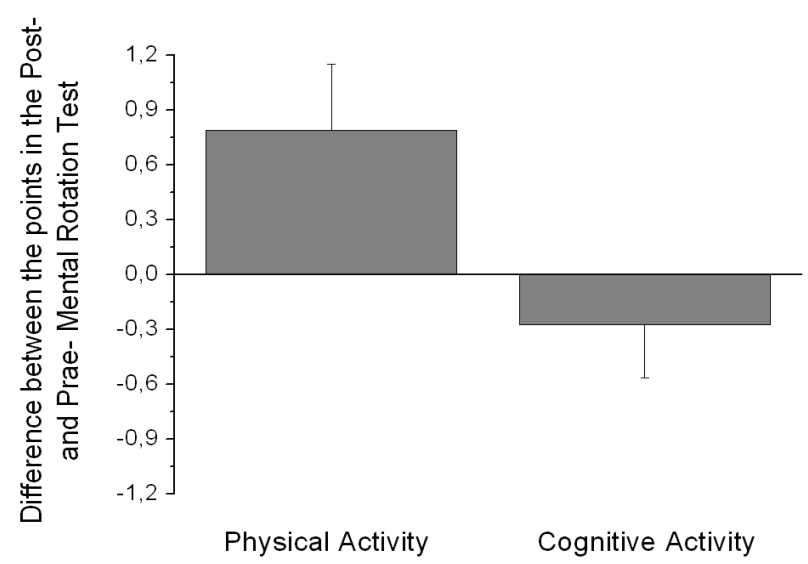

Figure 2. The difference score between the post- and praemental rotation test. The figure shows that participants in the physical activity group received more points in the Post Mental rotation test than in the pre-test, whereas the participants of the cognitive activity group did not. Error bars indicate standard errors

given in written form, followed by three training items so that participants became familiar with the task. The correct solutions of these training items were shown at the end of the page. Participants were instructed to attempt a solution for all 12 items within three minutes.

In this study the original test was used but the second set of 12 items was presented only after 45 minutes. In these 45 minutes participants of the physical activity group received physical activity lesson which comprises different activities as running, jumping, rope skipping and callisthenics. The participants of the cognitive activity group attended a lecture on kinematics, where they were allowed to ask something and to answer questions. The post mental rotation test was completed directly after the 45 minutes lasting physical or oral lesson.

\subsection{Statistical Analysis}

The standard scoring method by Peters et al. [16] was used: One point was given if and only if both correct sample stimuli of a target figure were marked correctly. Thus, participants could obtain 24 points maximum, 12 points in each test (pre-test, before the activity, and post-test after the activity).

Thus, a one-factorial design with the between-subject factor group (EG: physical activity, CG: cognitive activity) was used. The dependent variable was 1) number of points in the first time of the MRT, to reveal that there is no difference between two groups at the beginning of the test and 2) the difference between the two groups the number of correctly answered items in the MRT-A between the post- and the pre-test.

\section{Results}

There was no difference between the two groups in the 
first part of the MRT, $F(1,87)=0.294$, n.s.

Regarding the difference score, an ANOVA revealed a significant main effect of Group $\mathrm{F}(1,87)=5.03, \mathrm{p}<0.05$, $\eta 2=0.06$.

Figure 2 shows, that the participants from the physical activity group $(M=0.73, \mathrm{SE}=0.31)$ improved their mental rotation performance whereas the participants from the cognitive activity $(M=-0.28, \mathrm{SE}=0.29)$ group did not.

\section{Discussion}

This study indicated the relation between physical activity and mental rotation performance. Participants improved their mental rotation performance after attending a sport class for 45 minutes. They did not improve their spatial performance when listening to an oral lesson between the two tests. Because we did not find an improvement in the cognitive activity group the post-pre improvement in performance after physical activity can not be expected from some kind of practice alone.

This study was a field experiment with a high ecological validity and the most possible intern validity. Both lessons were real educational settings. The lessons were chosen because of their high comparability concerning the duration, the time in the morning, they started and the level of social participation. It was the first step in a real educational setting investigating the importance of physical activity on one specific cognitive task. Further studies have to follow which examine the relevant factors for the obtained results. A measurement of physical and cognitive effort may be used in the following studies.

This result might have important implications for different disciplines, for sport science, psychology and especially for education. For people working in sport science it is important to see, that a sportive training does have this supporting effect on a cognitive task. That means in other words that sport might support not only physical but also cognitive fitness. For cognitive psychologists the assumed link between cognitive and motor processes is supported. Furthermore, this study has practical implications for educational science: It supports the claim for more physical activity in school, knowing that also cognitive learning will be enhanced by that. If one takes these results seriously school systems have to reassess their school curricula. Does it make any sense to have one cognitive lesson after the other one - for six to ten hours the day? These results provide evidence that physical activity between school lessons might be indispensable to obtain optimal cognitive performance in children.

Mental rotation is only one cognitive task, there are a lot of other ones like for example attention and memory tasks. Beside this there seems to be a link between mental rotation ability and math performance, as suggested by the work of e.g. Casey, Nuttall and Pezaris [22]. Therefore, one might speculate that motor learning might also enhance maths performance. First evidence comes from a study of Nilges [23] who outlined 6 spatial abilities, which mediated both physical and mathematical learning. Further empirical studies should investigate this relation between physical activity and mathematic performance in more detail.

This is only one study investigating experimentally the influence of physical activity on cognitive performance. The advantage of this study is the real educational situation setting. Other studies have to follow where this influence is investigated in more detail. Is the effect still reliable if the second mental rotation test is not presented directly after the cognitive or physical activity? Is this effect also evident in children at school-age? Does this improvement hold true for different kinds of physical activity? More studies in this area might have a great influence on physical and cognitive education in schools.

\section{Acknowledgements}

This study was supported by the German Research foundation. We thank Michael Peters for his friendly permission to use the Mental Rotation Test (MRT) in our work group. We thank our student assistants for their help during data acquisition.

\section{REFERENCES}

[1] J. Piaget, "The Origins of Intelligence in the Child (1936, 1963)," (La naissance de l'intelligence chez l'enfant, M. Cook, Trans.), International Universities Press, W.W. Norton \& Company, New York, 1956.

[2] A. Sheya and L. B. Smith, "Development through Sensory-Motor Coordinations," Manuscript Submitted for Publication, 2008.

[3] L. B. Smith, E. Thelen, R. Titzer and D. McLin, "Knowing in the Context of Acting: The Task Dynamics of the A-not-B Error," Psychological Review, Vol. 106, No. 2, 1999, pp. 235-260.

[4] C. Fabre, K. Chamari, P. Mucci, J. Massé-Biron and C. Préfaut, "Improvement of Cognitive Function by Mental and/or Individualized Aerobic Training in Healthy Elderly Subjects," International Journal of Sports Medicine, Vol. 23, No. 6, 2002, pp. 415-421.

[5] C. Gillberg, "Deficits in Attention, Motor Control, and Perception: A Brief Review [Oct]," Archives of Disease in Childhood, Vol. 88, No. 10, 2003, pp. 904-910.

[6] M. R. Leary, "Moving on: Autism and Movement Disturbance," Mental Retardation, Vol. 34, No. 1, 1996, pp. 39-53.

[7] T. M. Pitcher, J. P. Piek and D. A. Hay, "Fine and Gross Motor Ability in Males with ADHD," Developmental Medicine and Child Neurology, Vol. 45, No. 8, 2003, pp. 525-535.

[8] J. L. Etnier, P. M. Nowell, D. M. Landers and B. A. Sib- 
ley, "A Meta-Regression to Examine the Relationship between Aerobic Fitness and Cognitive Performance," Brain Research Reviews, Vol. 52, No. 1, 2006, pp. 119130.

[9] J. Etnier, W. Salazar, D. Landers and S. Petruzello, "The Influence of Physical Fitness and Exercise upon Cognitive Functioning: A Meta-Analysis," Journal of Exercise \& Sport Psychology, Vol. 19, No. 3, 1997, pp. 249-277.

[10] A. Diamond, "Interrelated and Interdependent," Developmental Science, Vol. 10, No. 1, 2007, pp. 152-158.

[11] J. J. Campos, D. I. Anderson, M. A. B. Roth, E. M. Hubbard, M. J. Hertenstein and D. Witherington, "Travel Broadens the Mind," Infancy, Vol. 1, No. 2, 2000, pp. 149-219.

[12] M. C. Linn and A. C. Peterson, "Emergence and Characterization of Sex-Differences in Spatial Ability: A MetaAnalysis," Child Development, Vol. 56, No. 6, 1985, pp. 1479-1498.

[13] R. N. Shepard and J. Metzler, "Mental Rotation of ThreeDimensional Objects," Science, Vol. 171, No. 972, 1971, pp. 701-703.

[14] D. C. Geary, S. J. Saults, F. Liu and M. K. Hoard, "Sex Differences in Spatial Cognition, Computational Fluency, and Arithmetical Reasoning," Journal of Experimental Child Psychology, Vol. 77, No. 4, 2000, pp. 337-353.

[15] M. Hegarty and M. Kozhevnikov, "Types of Visual-Spatial Representations and Mathematical Problem Solving," Journal of Educational Psychology, Vol. 91, No. 4, 1999, pp. 684-689.

[16] M. Peters, P. Chisholm and B. Laeng, "Spatial Ability, Student Gender and Academic Performance," Journal of
Engineering Education, Vol. 84, No. 1, 1995, pp. 69-73.

[17] P. Jansen, C. Titze and M. Heil, "The Influence of Juggling on Mental Rotation Performance," Journal of International Sport Psychology, Vol. 40, No. 1, 2009, pp. 351-359.

[18] M. Wraga, W. L. Thompson, N. M. Alpert and S. M. Kosslyn, "Implicit Transfer of Motor Strategies in Mental Rotation," Brain and Cognition, Vol. 52, No. 2, 2003, pp. 135-143.

[19] B. Draganski, C. Gaser, V. Busch, G. Schuierer, U. Bogdahn and A. May, "Neuroplasticity: Changes in Grey Matter Induced by Training," Nature, Vol. 427, No. 6972, 2004, pp. 311-312.

[20] K. Jordan, J. Heinze, K. Lutz, M. Kanowski and L. Jäncke, "Cortical Activations during the Mental Rotation of Different Visual Objects," Neuroimage, Vol. 13, No. 1, 2001, pp. 143-152.

[21] S. G. Vandenberg and A. R. Kuse, "Mental Rotations, a Group Test of Three-Dimensional Spatial Visualization," Perceptual and Motor Skills, Vol. 47, No. 2, 1978, pp. 599-604.

[22] M. Casey, R. L. Nuttall and E. Pezaris, "Mediators of Gender Differences in Mathematics College Entrance Test Scores: A Comparison of Spatial Skills with Internalized Beliefs and Anxieties," Developmental Psychology, Vol. 33, No. 4, 1997, pp. 669-680.

[23] L. Nilges, "The Role of Spatial Ability in Physical Education and Mathematics," The Journal of Physical Education, Recreation \& Dance, Vol. 71, No. 6, 2000, pp 29-32. 